\title{
What Do Population-Level Welfare Indices Suggest About the Well-Being of Zoo Elephants?
}

\author{
Georgia J. Mason ${ }^{1 *}$ and Jake S. Veasey ${ }^{2}$ \\ ${ }^{1}$ Canada Research Chair in Animal Welfare, Animal Science Department, \\ University of Guelph, Guelph, Ontario, Canada \\ ${ }^{2}$ Head of the Department of Animal Management and Conservation, \\ Woburn Safari Park, Woburn, Bedfordshire, United Kingdom
}

\begin{abstract}
To assess zoo elephants' welfare using objective population-level indices, we sought data from zoos and other protected populations (potential "benchmarks") on variables affected by poor well-being. Such data were available on fecundity, potential fertility, stillbirths, infant mortality, adult survivorship, and stereotypic behavior. Most of these can also be affected by factors unrelated to well-being; therefore, for each, we analyzed the potential role of these other factors. Population-level comparisons generally indicate poor reproduction, and poor infant and adult survivorship in zoos compared with benchmark populations (with some differences between zoo regions and over time). Stereotypic behavior also occurs in c. $60 \%$ of zoo elephants; as the population-level welfare index least open to alternative interpretations, this represents the strongest evidence that well-being is/has been widely compromised. Poor well-being is a parsimonious explanation for the diverse range of population-level effects seen, but to test this hypothesis properly, data are now needed on, for example, potential confounds that can affect these indices (to partition out effects of factors unrelated to well-being), and causes of the observed temporal effects, and differences between species and zoo regions. Regardless of whether such additional data implicate poor well-being, our findings suggest that elephant management has generally been sub-optimal. We also discuss the selection and utilization of benchmark data, as a useful future approach for evaluating such issues. Zoo Biol 29:256-273, 2010. $\quad$ (c) 2010 Wiley-Liss, Inc.
\end{abstract}

Keywords: stress; captivity; stereotypic behavior; longevity; acyclicity

\footnotetext{
*Correspondence to: Professor Georgia J. Mason, Canada Research Chair in Animal Welfare, Animal Science Department, University of Guelph, Guelph, Ontario, Canada N1G 2W1. E-mail: gmason@uoguelph.ca
}

Received 10 October 2009; Revised 28 November 2009; Accepted 8 December 2009

DOI 10.1002/zoo.20303

Published online 5 February 2010 in Wiley InterScience (www.interscience.wiley.com). 


\section{INTRODUCTION}

Do zoo elephants have adequate welfare? Some animal protection groups argue that thwarted natural behavior patterns, the lack of control and freedom in captivity, and persistent health problems, all compromise zoo elephants' well-being — but such claims are typically forcefully rebutted by zoo personnel. To try and address this issue objectively, we compare the available data on animal-based welfare indices for zoo elephants and other protected populations. As in our companion article (this volume), we use "welfare" and "well-being" interchangeably to mean feelings-based states. Welfare is thus impaired if poor health causes feelings like pain or nausea, or if animals' circumstances induce states, such as anxiety, fear, or feelings of stress; while welfare is good if animals experience relaxation, satisfaction, and other positive feelings. Such "affective" states cannot be measured directly, only inferred from indirect indices [see Mason and Veasey, this volume].

We use a subset of such indices here: those for which data were available from both zoos and comparable "benchmark" populations. Benchmark data were required because to judge whether zoo populations have good, acceptable, or poor welfare, reference values are needed. Wild populations subject to human encroachment, drought, or poaching pressure, we deemed unsuitable as benchmarks. Their welfare and performance fell far below the aspirations of good zoos. Nor did we use data from unspecified or pooled wild populations, because these still represent a wide range of welfare states. Instead, we used other protected (in situ) populations as benchmarks: those with standards of protection and performance that zoos should meet or exceed. This approach assumes that zoos aim for excellent welfare; it also recognizes that protecting wild animals in situ is the complement to protecting them in captivity. It specifically addresses whether zoo elephants are faring as well as one would expect given that they are well-provisioned, protected from danger, and receive veterinary treatment. If they are, then claims of population-level poor welfare would not be supported.

Following earlier researchers [e.g. Kurt and Mar, 1996; Taylor and Poole, 1998; Clubb et al., 2008, 2009; Harris et al., 2008; Saragusty et al., 2008], in practice this meant using data from in situ sanctuaries/"orphanages" and protected reserves, as well as working (logging) populations. All experience the potential benefits of a "natural" life (appropriate climate, near-species-typical behavioral opportunities, etc.) while being largely protected from welfare risk factors, such as starvation or poaching. Timber camp animals can experience poor welfare [e.g. Lair, 1997; Hedges et al., 2006], but we sought well-managed populations and/or those from which sources of harm could be removed statistically. For both these and zoo populations, comparative welfare index data existed for fecundity, fertility as manifest in acyclity, various measures of survivorship, and stereotypic behavior. These were briefly reviewed in our companion article, but here we provide more evidence of their links with well-being, as well as detailing other factors, both extrinsic and intrinsic, which can affect them independently of welfare. This is important because while the perfect index would "cleanly" reflect elephants' affective states (in a linear, interval-scaled way, without false positives or negatives), realistically most indices are far from this ideal. We must consider our indices' limitations, if we are to make valid inferences about the welfare implications of any population differences. In each of the following sections, we therefore first compare zoos with other populations, before discussing whether differential welfare is the only possible explanation for any differences. 


\section{Mason and Veasey}

\section{POPULATION-LEVEL POTENTIAL WELFARE INDICES}

\section{Potential Welfare Index I: Fecundity}

Age-specific fecundity (female calf output per dam) in the Asian elephants of European zoos, between 1960 and 2005, averaged c. 0.01 at their reproductive peak (12-30 years of age) [Clubb et al., 2009]. In contrast, Myanma Timber Enterprise (MTE) animals working in Burma had higher peak fecundity-about 0.05 between 15 and 45 years of age - and breeding continued into their late 40s rather than ceasing in their early 30s [Clubb et al., 2009; see their Fig. 1A]. African elephants' average fecundity in European zoos averaged c. 0.015 at peak reproduction (12-30 years of age). This species' zoo data again contrasted similarly with a benchmark population, with fecundity in Amboseli National Park varying from 0.05 to 0.14 (averaging at about 0.08 between 15 and 45 years); and Amboseli females breeding into their early 50s instead of ceasing at around 30 [Clubb et al., 2009; see their Fig. 1B]. This estimated Amboseli average of 0.08 is the same as that calculated by Sukumar et al. [1997] for Tamilnadu Forest Department working elephants, and is similar to the "0.1" of Pinnewala Orphanage Asian elephants [Taylor and Poole, 1998]. It represents one female calf per dam every c. 12 years: thus a calf of either sex every c. 6 years. This is approaching the maximum reproductive output: in very good conditions female elephants can calve every 4-5 years [and for most of their adult lives: Sukumar, 2003; Lee and Moss, 2008]. Zoo elephants' reproductive rate is clearly far below this optimum.

Such poor fecundity could indicate poor well-being if it reflected certain intrinsic biological changes, especially reduced ovulation rates, low libido, and/or low conception rates caused by stress-related physiological changes. Human epidemiological studies and experiments on other mammals reveal that ovulation rates, sperm quality, low libido, and conception rates are all compromised by stress. General reviews [e.g. Wingfield and Sapolsky, 2003; von Borell et al., 2007] were referenced in our companion article, but here we give more specifics, focusing on libido and conception rates, because ovulation and reproductive senescence are considered in the next section. To give just some examples, in humans, stressors reduce sexual desire, and anxiety and low libido statistically co-vary [e.g. Hartmann et al., 2002], whereas in mice, social stress reduces the courtship male mice show to females [e.g. Sugiura et al., 1997]. Negative effects of psychosocial stress and cortisol on male fertility (e.g. via sperm motility) occur across species from fish to humans [e.g. Sheiner et al., 2003; Rurangwa et al., 2004]. Female fertility is affected by wellbeing too. Again in humans, improved mood is linked with greater conception rates, independent of coital rates [Sanders and Bruce, 1997], whereas in many other species, experimentally-imposing stressors (e.g. frightening stimuli) upon reproductive age females reduces successful implantations and increases early fetal/blastocyst loss rates [e.g. Wiebold et al., 1986].

However, a problem with simple fecundity comparisons between zoos and other populations is that they cannot distinguish between these sorts of intrinsic factors, and extrinsic factors such as opportunities to mate. Lack of access to males is a major factor affecting fecundity in zoo elephants. Much of zoo elephants' low fecundity has simply arisen from management strategies limiting mating opportunities [e.g. Faust et al., 2006]. To assess whether stress/poor well-being really contributes to zoo elephants' low fecundity, one would need to either statistically 
control for female access to males or measure more directly relevant variables, such as persistent refusals to mate several potential partners, sperm count, early fetal losses, or anovulation (see below).

\section{Potential Welfare Index II: Anovulation and Reproductive Senescence}

Ovulation rates, manifest as irregular cycles or periods of acyclicity, have been investigated via endocrine surveys across North America [e.g. Brown et al., 2004a,b; Proctor et al., 2009, this volume] and Europe [e.g. Oerke et al., 2000, 2001; Oerke, 2004]. The most recently published American survey [2005s data: Proctor et al., this volume] revealed $30 \%$ of SSP African females to be acyclic and so unable to conceive, and 13\% SSP of Asian females. The most recent European survey (2008's data: Oerke, personal communication, May 2009) found less acyclicity: only $13 \%$ $(16 / 122)$ of African and 5\% (8/150) of Asian females were affected. This apparent difference between continents could merely reflect that European samples are voluntarily submitted for assay; thus very young and old animals, not considered reproductive, are minimally represented. North American data, in contrast, come from nearly all females, even prepubescent or middle-aged. To correct for this, we extracted figures for North American SSP animals aged from 11 to 35 from Proctor et al. [this volume], arguably more equivalent to European samples. In this age range, 32\% North American African females (24/75) were still acyclic, but only 4\% (2/49) of Asian females. Thus, focusing only on animals of prime breeding age, Europe and North America do not differ in acyclicity for Asians (chi-squared: NS), with very few (c. 1/20) being affected. However, the regions $d o$ still differ for African elephants, acyclicity being more prevalent in North America $\left(\chi^{2}=12.12, \mathrm{df}=1\right.$, $P=0.005) .{ }^{1}$ Furthermore, this problem in North America has become more widespread since 2002, even in the "reproductively aged" subpopulation [Proctor et al., this volume] (see footnote 1).

Is this acyclity in female African zoo elephants problematic? Equivalent endocrine data are not available from benchmark populations, but in good conditions $95 \%$ of wild African adult females are pregnant or lactating, thus clearly fertile [Gobush et al., 2008; also see Lee and Moss, 2008]. This indicates that the acyclity and thence infertility evident at least in North America, is abnormal for this species. In Asian elephants, acyclity is also associated with the marked decline in fecundity shown in zoos - not in benchmark populations - after the age of 35 (see previous section). Thus, unlike African elephants where the acyclic proportion stays rather stable up to 35 and beyond, in Asian females, post-35, the percent acyclic significantly increases to $16.2 \%(6 / 37)$ [Proctor et al., this volume]. Proctor et al. [this volume] shed further light on zoo elephants' premature reproductive senescence, by showing that in both species the proportion of animals with reproductive tract pathologies (e.g. cysts) increases in dams older than 30. Declines in fecundity with age in zoos thus do appear to have a biological basis.

\footnotetext{
${ }^{1}$ The as-yet-unpublished 2008 survey of North America shows less acyclicity in Africans aged 11-35: 18/73 (25\%; J. Brown personal communication, May 2009); however this is still higher than 2008's figures from Europe: $\chi^{2}=4.23, \mathrm{df}=1, P=0.040$.
} 


\section{Mason and Veasey}

Could poor well-being play a role here? Poor welfare can impair ovulation in other species. For example, in rats, experimentally imposed restraint (highly aversive to rodents) impairs luteinizing hormone release and thence ovulation [Roozendaal et al., 1995], whereas chronic stress (both as self-reported and indexed by elevated cortisol) can induce anovulation in human females [Berga et al., 2000]. Chronic stress can impair ovulation in other primates too, and accelerate reproductive senescence [e.g. Kaplan and Manuck, 2004]. Stress is also implicated in the early reproductive senescence of isolated or spontaneously stress-reactive rats [i.e. neophobic, with elevated corticosteroid responses; LeFevre and McClintock, 1991; Cavigelli et al., 2006] and evident in poultry denied environmental enrichment [Leone and Estévez, 2008]. However, factors not closely linked to welfare can also influence ovulation rates; these include reproductive suppression in order to assist related conspecifics [which in some species is not stress-related; e.g. Creel and Waser, 1994], and also very high or low body fat [e.g. Baird et al., 2006].

Whether poor welfare plays a role in acyclity in elephants is uncertain. In support of this "low welfare" hypothesis, hyper-prolactinemia occurs in many acyclic African females [reviewed in Mason and Veasey, this volume]. Thanks to apparent links with status and temperament, it has also been proposed that acyclicity stems from the demands of being dominant in the artificial, unrelated groups of captivity [Freeman et al., 2004, 2009]. Although this latter effect seems not to hold for Europe (Oerke, personal communication, May 2009), here other disturbances, such as keeper changes, inter-zoo transfer, and building noise, have been suggested as important - at least for Africans (Oerke, personal communication, May 2009). Wildcaught females, presumably more stressed, are also reportedly less likely to cycle than zoo-born females (Oerke, personal communication, May 2009). However, there is also evidence against the "low welfare" hypothesis. Cortisol is not elevated in acyclic animals, and nor is prolactin in many affected animals [reviewed by Mason and Veasey, this volume; J. Brown, personal communication, May 2009]. Furthermore, inter-zoo transfer seems not to be a risk factor for African females in North America, with long periods of residence in one location instead being important [Freeman et al., 2009]. Furthermore, dam status seems not to be important, if other factors are statistically controlled for [Freeman et al., 2009]; and in these newest analyses, excessive body fat has now emerged as a key issue. The lack of early breeding (simply owing to management) has also been argued to accelerate zoo elephants' reproductive senescence [reviewed by Mason and Veasey, this volume]. Thus, overall, if stress plays a role in zoo elephants' acyclicity and early reproductive senescence, it is only as part of a complex suite of other factors.

\section{Potential Welfare Index III: Stillbirth Rates}

For Asian elephants, Taylor and Poole [1998] calculated stillbirth rates of $25 \%$ (23/92) from questionnaire returns from 46 European and North American zoos. This compared with $0 \%(0 / 11)$ for Pinnewala Orphanage, 3\% for Tamilnadu Forestry elephants $(7 / 227)$, and " $<3 \%$ " for MTE elephants (calculation unclear). Clubb et al. [2008], focusing on female calves only (as relevant for population viability), present infant loss rates in European zoos, MTE, and Amboseli (see their Table S1). From these data, stillbirth and premature loss rates can be calculated. For African elephants, stillbirth and premature loss rates in European zoos and 
Amboseli do not differ ( $<4 \%$ in all cases). The same holds for multiparous Asian females in European zoos and MTE $(<4 \%)$. However, for primiparous Asian females, stillbirth and premature loss rates are significantly higher in European zoos than in the benchmark population $\left(8 / 24 \mathrm{cf} .13 / 270: \chi^{2}=27.12, \mathrm{df}=1, P<0.0001\right)$.

Does this finding indicate poor welfare, at least in the inexperienced mothers of this one species? Examples of the role of poor well-being in stillbirths and premature delivery include data from humans; for example, women with high levels of selfreported stress have significantly elevated risks of stillbirths [Wisborg et al., 2008], and stress can also induce preterm delivery [Lockwood, 1999]. However, obesity (both maternal and fetal) and dystocia additionally affect stillbirth rates in many species; and at least in Asian elephants, large neonates and overweight mothers are indeed known risk factors [reviewed Clubb et al., 2009]. Dystocia and stillbirth rates also seem to be particularly elevated in primiparous zoo elephants who first calve when aged 30 years or older [Doyle et al., 1999 as cited by Hermes et al., 2008]. Hermes et al. [2008] account for this in terms of the physical characteristics of such animals - not psychological factors related to affective state. Thus, overall, it is unknown whether or not poor well-being plays a role in the high stillbirth rates of first-time Asian elephant mothers in Europe (equivalent North American data are not published) and there are plenty of alternative plausible explanations.

\section{Potential Welfare Index IV: Infant Mortality Rates}

For Asian elephants, infant mortality rates in zoos are two-three times higher than in in situ logging enterprises (Table 1). However, the infant mortality data used by Saragusty et al. [2009] spanned the period 1962-2006, and toward the end of this period mortality apparently decreases (statistical significance not assessed) for Asian calves in Europe [although not in North America; see Figs. 1a and b of Saragusty et al., 2009]. For African elephants, the picture is more optimistic still in Europe. In the last c. 45 years, first year infant mortality rates for liveborn female calves here have averaged c. $23 \%$ for primiparous mothers and $0 \%$ for the few multiparous mothers: not significantly different from Amboseli [Clubb et al., 2008]. Saragusty et al. [2009]; calculated death rates (including stillbirths) up to 5 years of age in elephants in Europe and North America, across all dams and for both sexes of calf. They reported African elephant losses of 21.3\% (19/89) in Europe, and again calf mortality has seemingly decreased since the mid 1990s in Europe (see their Fig. 1c). However, for North American zoos, the equivalent figure for African elephants is $44.9 \%(22 / 49)$, and we calculate that this difference between the regions is significant $\left(\chi^{2}=4.35, \mathrm{df}=1, P=0.037\right)$. Furthermore, nor has there been any sign of improvement in recent years in North America (see Fig. 1d in Saragusty et al., 2009).

Overall, infant mortality rates in zoos are thus higher than they should be for Asian elephants and for African elephants in North America. Whether the same holds for African elephants in Europe depends on the benchmark comparator used. The lack of difference from Amboseli is reassuring. However, other protected populations seem to have less infant mortality than Amboseli, e.g. 10\% over the first 5 years in Kenya's Samburu reserve park [Wittemyer et al., 2005], suggesting that Amboseli might not represent a high benchmark. Furthermore, Saragusty et al. [2009] examined extrinsic causes of mortality in MTE animals, factoring out all those that should not occur in zoos (e.g. snake bites, etc.; see Discussion). Without these, 
TABLE 1. Infant mortality in Asian elephants

\begin{tabular}{|c|c|c|c|}
\hline & Clubb et al. [2008] ${ }^{\mathrm{a}}$ & $\begin{array}{l}\text { Saragusty et al. } \\
{[2009]^{\mathrm{b}}}\end{array}$ & $\begin{array}{c}\text { Data available from similar } \\
\text { populations? }\end{array}$ \\
\hline Western zoos & $\begin{array}{l}\text { Primiparous dams: } \\
\text { liveborn only } 37.5 \% \\
(6 / 16)^{\mathrm{c}} \\
\text { Primiparous dams: total } \\
\text { including stillbirths } \\
58.3 \%(14 / 24)^{\mathrm{d}} \\
\text { Multiparous dams: } \\
\text { liveborn only } 18.5 \% \\
(5 / 27)^{\mathrm{e}} \\
\text { Multiparous dams: total } \\
\text { including stillbirths } \\
21.4 \%(6 / 28)^{\mathrm{f}}\end{array}$ & $\begin{array}{l}\text { European zoos: } \\
\text { 41.5\% }(81 / 195) \\
\text { North American } \\
\text { zoos: } 39.6 \% \\
(61 / 154)\end{array}$ & $\begin{array}{l}\text { North American SSP data } \\
\text { (zoo-born calves only, } 0-1 \\
\text { year old): Female calf } \\
\text { infant mortality }=48 \% \\
(23 / 48), \text { male calf infant } \\
\text { mortality }=40 \%(19 / 47) \\
\text { [Faust et al., } 2006]\end{array}$ \\
\hline $\begin{array}{l}\text { Myanma } \\
\text { Timber } \\
\text { Enterprise } \\
\text { (MTE) }\end{array}$ & $\begin{array}{l}\text { Primiparous dams: } \\
\text { liveborn only } 13.2 \% \\
\left(^{2} / 257\right)^{\mathrm{c}} \\
\text { Primiparous dams: total } \\
\text { including stillbirths } \\
17.4 \% \\
(47 / 270)^{\mathrm{d}} \\
\text { Multiparous dams: } \\
\text { liveborn only } 7.0 \% \\
(30 / 430) \\
\text { Multiparous dams: total } \\
\text { including stillbirths } \\
9.5 \% \\
(42 / 442)^{\mathrm{f}}\end{array}$ & $24.0 \%(738 / 3,070)^{\mathrm{g}}$ & $\begin{array}{l}\text { Tamilnadu Forest } \\
\text { department: first year } \\
\text { infant total } \\
\text { mortality }=19.4 \%(45 / \\
\text { 232) [Sukumar et al., } \\
\text { 1997]. Of live births only, } \\
\text { deaths up to 5 years: } 6.8 \% \\
\text { (15/220) [Taylor and } \\
\text { Poole, 1998] }\end{array}$ \\
\hline
\end{tabular}

aOnly data from zoo-bred female calves were used, and "infant" deaths were up to 1 year of age. Data were split by dam parity to ensure that any population differences were not a byproduct of the percent dams who were first-time breeders (thus calves born to dams of unknown parity were excluded); zoo data came from Europe, 1960-2005. MTE data came direct from the MTE studbooks, and as used in Mar [2007], thus revised and corrected over those used in Mar [2002]. Furthermore, only data from captive-bred female calves from dams of known parity were used.

${ }^{\mathrm{b}}$ Data from both sexes of zoo-born calves were used, including still-births and premature births; "infant" deaths were up to five years of age; zoo data came from the period 1962-2006, and while no tests were run to assess whether this effect was significant, for Asian calves in Europe-but not in North America - there seems to have been a nonlinear increase in survivorship, with accelerating improvements in the last 5-10 years (though it is unclear whether this simply reflects an increasing percent of multiparous dams).

${ }^{\mathrm{c}} \mathrm{Zoo}>\mathrm{MTE}, P<0.05$.

d Zoo $>$ MTE, $P<0.0001$.

${ }^{\mathrm{e} Z} \mathrm{Zoo}>\mathrm{MTE}, P<0.05$.

${ }^{\mathrm{f}}$ Trend for Zoo $>$ MTE: $P<0.10$.

${ }^{\mathrm{g}}$ Saragusty et al. used MTE data from a secondary source [Mar, 2007] on deaths before the age of 5 .

MTE infant mortality similarly dropped to about $10 \%$. Saragusty et al. therefore, argue that for both species, infant losses in zoos should be no greater than $10 \%$. Despite this note of caution, however, we perhaps still should be optimistic about infant deaths in Europe, particularly in African elephants. 
Infant mortality is a potential welfare index for breeding females, because it increases in many species when dams are exposed to aggression, frightening stimuli, or other sources of stress. To illustrate, repeatedly exposing pregnant sows to restraint causes poor welfare, as evidenced by escape attempts and immunosuppression. Post-natally, it increases later mortality in the litter, in part by reducing IgG in the milk [Tuchscherer et al., 2002]. Similar effects occur in rats exposed to cat odor when pregnant (this induces fear responses and elevates cortisol), but here, poorer pup survivorship seems caused by altered maternal behavior [Patin et al., 2002]. Indeed, acute stressors or poor environments can even trigger infanticide [see e.g. Ahlström et al., 2002, on piglet-savaging by sows]. Individual differences in stress, as assessed by corticosteroid levels, can also predict poor maternal care. For instance, amongst gorillas in zoos, females with high postpartum cortisol concentrations spend less time caring for and carrying their newborn infants [Bahr et al., 1998]. However, many factors unrelated to dam wellbeing also affect infant mortality, including congenital defects, and also dam experience [e.g. Zedrosser et al., 2009].

Whether the high calf death rates of some zoo elephant populations reflect poor dam well-being is unknown. Nor is it known whether the apparent recent improvements in European calf survivorship represent improvements in dam welfare (vs. other improvements in husbandry such as better veterinary care, or other factors such as increased numbers of experienced mothers across the population). Differences in the prevalence of infanticide [very rare in MTE and Amboseli; see e.g. Clubb and Mason, 2002] do suggest that stress could play a role, at least when this form of infant death is seen. Even were this confirmed, it need not reflect lifelong, pre-existing welfare problems in the dam, but instead short-lived acute stress introduced by management strategies around birth (social isolation, chaining, etc.). In addition, many factors, quite unrelated to dam well-being, seem likely to increase infant mortality in general in zoo calves. These include effects of dystocia on calves, poor maternal competence that is simply a product of being primiparous and/or not housed or raised with other calves [see Mason and Veasey this volume], and in Asian elephants, Elephant Endothelial Herpes Virus. To pinpoint stress per se, one would therefore need data on potential confounds, to analyze the causes of infant deaths in zoo and "benchmark" populations, and to examine intervening variables likely to be affected by stress (e.g. milk IgG, and maternal oxytocin and cortisol).

\section{Potential Welfare Index V: Overall Survivorship}

Adult survivorship and overall expected lifespans in zoos are a controversial topic. Survivorship curves in Kurt [1995] for female Asian elephants showed median lifespans of c. 33 years for MTE animals and c. 20 for wild, free-living animals, but just c. 10 years for captive-born zoo animals. Clubb and Mason [2002] arrived at somewhat similar figures for MTE and European zoo animals. Their calculations were correctly criticized as simplistic by Wiese and Willis [2004], who calculated life expectancy for Asian elephants in Europe and North America and African elephants in North America, using life-table analysis as well as survival analyses that excluded infant mortality. They calculated median life expectancy via life-table analysis for female Asian elephants at 35.9 years in North America and 41.9 years in Europe; and average life expectancy from their survival analyses (excluding infant losses) at 44.8 years in 


\section{Mason and Veasey}

North America and 47.6 years in Europe. The North American African elephant average life expectancy was also estimated from survival analyses to be 33 years.

However, the Wiese and Willis calculations are problematic, especially in terms of how figures were compared with values from reference populations. Although first-year infant mortality was omitted from survival analysis estimates, some of the results were presented as "average life expectancies" and compared with reference population values which did include infant mortality. This is important because, as we have seen, infant mortality is high in these zoo populations. Omitting it thus inflates calculated life expectancies. Comparable Amboseli figures, to illustrate, would thus similarly exclude infant mortality (doing this yields an Amboseli female mean of 44 years, and a male mean of 30; P. Lee, personal communication, March 2009). Furthermore, the sex ratio of populations under comparison should be taken into account, because the zoo population is so heavily female-skewed. Truly comparable Amboseli figures, in this case, should therefore also be calculated as if the reference population is $80 \%$ female (like the zoo population) rather than $50 \%$. The resulting value $([44 \times 0.8]+[30 \times 0.20])$ is 41 years, substantially higher than the male/female midpoint of 32.5 years that Wiese and Willis calculated from earlier Amboseli data and informally compared with their zoo estimate of 33 years.

Clubb et al. [2008] performed analyses using data from 4,500 animals to compare female elephant survivorship in European zoos over nearly five decades, with that in MTE populations and Amboseli National Park. The summary figures they calculated were as follows: including infant mortality, median lifespans for Asian female elephants were 19 years in zoos and 42 years in MTE [the latter being similar to the median of c. 45 years earlier calculated for Tamilnadu Forestry animals by Sukumar et al., 1997]; whereas median lifespans for African elephants were 17 years in zoos and 36 years in Amboseli (56 years, if deaths caused by humans were excluded). However, median figures like these are merely descriptive and also, of necessity, they came only from animals with complete histories from birth. The statistical comparison of zoo and benchmark populations, in contrast, required separating juvenile and adult phases of the lifespan (to meet the tests' "proportionality" assumptions). These statistical comparisons also allowed the inclusion of wildcaught animals, regardless of their age of entry to the zoo populations. Wild-caught juvenile Asians survive better in zoos than in MTE, because many of the latter animals die of "capture stress." In adulthood, survivorship of these animals is then not significantly different, unless "capture stress" is statistically controlled for (as a cause of death that should be absent from zoos). Then, those adult MTE wild-caught adults who survive the vulnerable post-capture period are shown to subsequently live significantly longer than wild-caught zoo adults. Turning to just captive-bred Asian elephants specifically, adult females in zoos have mortality risks more than four times higher than captive-bred MTE adult females (a significant difference). African elephants as adults also had significantly higher mortality risks in zoos than in Amboseli, evident even when "low benchmark" data were used (i.e. Amboseli data that included deaths caused by humans). However, their survivorship did show significant improvement over the 45 years of zoo records.

Altogether, these various survivorship studies suggest that survivorship in the European zoo populations, and perhaps also the North American (statistical comparisons are now needed here), has been poorer than one would expect over the last 4-5 decades. However, there have been significant improvements in recent years 
for adult African elephants in European zoos. Overall, such effects could [see Mason and Veasey this volume; Clubb et al., 2009] reflect differential stress levels; thus, very poor well-being in wild-caught juvenile MTE animals and poor well-being in zoo adults of both species, with improving well-being in most recent years in the European African population. However, other effects could be at work too. We therefore now detail some specific examples where poor welfare has curtailed lifespans across a range of species, before discussing other contributory factors that influence survivorship post-infancy.

Chronic and acute stress can both reduce adult lifespan, this effect being best studied in humans and rats. In the elderly, reports of not feeling in control predict elevated mortality rates [Menec and Chipperfield, 1997], and experiencing a house break-in also doubles the risks of dying in the 2 years after the crime compared with non-burgled neighbors [Donaldson, 2003]. Kiecolt-Glaser et al. [2002] and Vitetta et al. [2005] reviewed many similar findings in humans, with stress and depression apparently curtailing adult lifespan via effects on endocrine stress axes, immune function, and other systems which increase risks of carcinoma, strokes, and cardiovascular and other diseases. Similarly, in rats, spontaneously stress-reactive individuals (i.e. neophobic, with elevated HPA responses) die earlier in adulthood [typically of cancer; Cavigelli and McClintock, 2003; Cavigelli et al., 2006]. Rats who are isolation-housed [Shaw and Gallagher, 1984], also die prematurely once adults hit "middle age."

We do not know if poor welfare similarly accelerates aging, senescence, and death in zoo elephants. There is certainly some evidence that stress can increase mortality rates in these animals, at least in Asian elephants. Wild-born Burmese elephants captured and "tamed" for logging die at faster rates than same-age captive-bred animals in the same working populations, and also faster than same-age wild-caught MTE animals who have survived for more than 8 years after these events [Mar, 2007; Clubb et al., 2008]. In zoos, the most likely examples of stress-related deaths are those seen following inter-zoo transfer [Clubb et al., 2008, 2009], although data on pretransfer health, stress physiology, and causes of death are needed to test this hypothesis. However, when it comes to the premature adult deaths of African and Asian elephants (especially zoo-bred individuals), other potential causal factors - not caused by poor psychological welfare - could include Herpes (in Asians) and obesity (both species). To know whether poor welfare per se accelerates death, it would thus be useful to know the relative severity and prevalence of various pathologies (e.g. cardiovascular disease), of disease risk factors [e.g. insulin resistance, IL-6, thymus involution, wound-healing rates; see Mason and Veasey, this volume; also Clubb et al., 2009], and of other physiological differences (e.g. HPA function) in zoo vs. benchmark populations. Unfortunately, such comparative data do not exist as yet.

\section{Potential Welfare Index VI: Stereotypic Behavior}

Clubb and Mason [2002], pooling data from published accounts, estimated that c. $40 \%$ of zoo elephants perform stereotypic behavior [for definition and examples see Mason and Veasey, this volume], spending on average $10 \%$ time in this behavior (15\% for Asian and 2\% for African elephants). More recently, Harris et al. [2008] collected behavioral data from the entire UK and Irish elephant population. Of the 77 animals observed in the daytime, 42 (54\%) showed stereotypic behavior. Prevalence did not apparently vary with species but time budget did, with Asian 


\section{Mason and Veasey}

elephants spending a mean of $6 \%$ day-time observations in this behavior, and African elephants, just $1 \%$. Estimates of prevalence and time-budget values increased, however, if nocturnal data were also collected; of the 41 animals observed for the full $24 \mathrm{hr}, 68 \%$ performed stereotypic behavior and for on average $9 \%$ of their time. These revised prevalence values resemble those obtained by surveying zoo keepers on their charges' behavior. Keepers reported that 22/30 (73\%) of their Asian and $17 / 28(61 \%)$ African elephants were stereotypic (an apparent slight species difference that is not statistically significant).

How does this compare to benchmark populations? Harris et al. applied the same day-time observation methods and "keeper" surveys as they used in zoos to working timber animals in Assam, India. From direct day-time observation, they inferred that none of the 42 subjects performed this behavior, but again greater prevalence was indicated by keeper knowledge: mahouts reported $21 \%(9 / 42)$ of these elephants to stereotype. We calculate this prevalence to be significantly lower than that reported for Asian elephants in the UK zoos $\left(\chi^{2}=19.23\right.$, $\mathrm{df}=1$, $P<0.0001)$. Stereotypic behavior has similarly been reported as rare in MTE elephants [Mar, 2007; K. Mar, personal communication, October 2008], although instances might have been overlooked here: behavior and welfare were not this work's focus, nor were MTE mahouts questioned. Quantitative data, unfortunately, do not exist for sanctuary animals or for free-living wild Asian or African elephants. However, a widely accepted judgment is that zoo elephants are more prone to unambiguous stereotypic behavior than their wild conspecifics. Thus, for example, when transient foot-swinging and other displacement activities occur in free-living African elephants [reviewed by Mason and Veasey, this volume], they are far less frequent and time-consuming than the repetitive movements performed in zoos [e.g. J. Poole, personal communication, March 2009; Harris et al., 2008 also cautiously report no stereotyping in a Botswana population studied by a collaborator].

Such contrasts are important because a recent meta-analysis of several hundred articles across a range of captive species [Mason and Latham, 2004], showed that empirically, those housing-types, aspects of husbandry (e.g. weaning age), and experimental treatments that increase stereotypic behavior typically also induce or increase other signs of poor well-being (e.g. avoidance/escape attempts, elevated HPA activity, increased infant mortality, etc.). Thus, populations in which stereotypic behavior is elevated, show significant increases in other signs of poor welfare compared with less stereotypic populations. This pattern is consistent with the apparent mechanisms underlying these activities: repeated attempts to perform frustrated, highly motivated behaviors and changes in forebrain structure and function stemming from stress and/or abnormal developmental environments [e.g. Wuerbel and Stauffacher, 1998; Hadley et al., 2006; Mason, 2006]. Overall, prevalent stereotypic behavior across zoo populations thus suggests that conditions are sub-optimal for many elephants or at least have been historically. Of all the indices reviewed in this paper, this one is hardest to account for via effects independent of well-being.

\section{DISCUSSION}

Our aim was to evaluate how zoo populations compare with others in terms of animal-based indices, to assess whether zoo elephants as a cohort appear to have good, adequate, or poor welfare. In practice, our considerations often left us 
uncertain as to the roles of well-being per se, because other factors like excess body fat or inadequate reproductive experience repeatedly emerged as plausible alternative explanations for population differences. Nevertheless, in summarizing our findings (Table 2), three things become clear. First, regardless of whether poor well-being is the underlying cause in each instance, zoo elephants show many undesirable responses from a management perspective. Second, these effects are sometimes impacted by "recency" (i.e. changes over time) and region (i.e. Europe vs. America), suggesting that variation in husbandry with time or location is influential. Third, the degree to which some variables appear sub-optimal sometimes depended on the reference data they were compared with (especially the degree of statistical correction for causes of harm that would be absent in optimally protected animals). Here we therefore synthesize and discuss our findings, suggest future research needs, and finally address some methodological issues raised by "benchmarking."

\section{What Do Potential Welfare Indices Reveal About Zoo Elephants' Well-Being?}

The low fecundity and premature reproductive senescence, high prevalence of acyclicity in African elephants (at least in North America), and high stillbirth rates of primiparous Asian dams could be caused by stress or other forms of poor welfare. However, other potential explanations appear equally valid (e.g. excess body fat, little access to mates, or cycling too often in early adulthood). Similarly, for elevated

TABLE 2. Are zoo elephant populations performing as well as should be expected?

Potential welfare index (Please see text

for discussion of non-welfare related

factors that can influence each index)

African elephants

(i) Fecundity ${ }^{\mathrm{a}}$

(ii) Fertility (cycling)

(iii) Still and premature births ${ }^{\mathrm{a}}$

(iv) Infant mortality

(v) Juvenile/adult survivorship ${ }^{a}$

(vi) Stereotypic behavior

No
North America: No ${ }^{b}$
Europe: Maybe

Europe: Maybe

Yes
North America: No
Europe: Maybe
(depends on
"benchmark"
used)
Juvenile: Yes
Adult: No ${ }^{d}$
No

Asian elephants

No
Yes (aside from
reproductive
senescence post 35 )

No: if primiparous

Yes: if multiparous

$\mathrm{No}^{\mathrm{c}}$

Juvenile: Yes

Adult: $\mathrm{No}^{\mathrm{e}}$

No

Differences between regional zoo subpopulations (Europe vs. North America), any temporal effects seen (e.g. improvements in recent years), and conclusions that vary according to the precise "benchmark" used are noted.

a Data from European zoos only.

${ }^{\mathrm{b}}$ Figures apparently worsening in recent years.

${ }^{\mathrm{c}}$ With figures apparently improving in recent years.

${ }^{\mathrm{d}}$ Although values have improved in Europe in recent years.

${ }^{\text {e}}$ Particularly if captive-born (whether wild-caught adults are performing to standard depends on which "benchmark" is used). 


\section{Mason and Veasey}

infant mortality (especially as seen in Asians, and the African elephants of North America), poor dam well-being could be the cause, but again alternative explanations are possible, such as lack of earlier experience with calves and (for Asians) Herpes. Adult survivorship in Europe (the North American population awaits valid comparison with reference populations) is also poorer than one would expect. Again, this could well reflect stress (especially Asian elephants' elevated risks of dying after inter-zootransfer), but factors not directly related to poor psychological welfare could well play a role too (e.g. being overweight, which could even reflect good well-being if animals actually prefer to exercise little and eat too much). It thus cannot currently be said which, if any, of these problems truly reflect poor well-being. The answer could even vary between the species, and/or between European and North American sub-populations.

The picture is clearer for stereotypic behavior. This is prevalent (if not very time-consuming), apparently occurring in at least $60 \%$ of zoo elephants. Some argue that unambiguous stereotypic behavior should simply never occur in zoos [Mason et al., 2007]. Even if this is seen as too stringent, working Asians, providing a less high benchmark, still perform significantly less than zoo conspecifics. With regards to population-level welfare assessments, this index is least open to alternative interpretations, so representing the strongest evidence that well-being is or has been compromised in a high proportion of zoo elephants.

In summary, several potential welfare indices show often striking differences between zoos and reference populations. This does not mean that it is impossible for zoos to achieve the same standards as benchmark populations or that no individual zoo has done so already; but at the population-level, zoos as a group have been underperforming. This suggests that, at the very least, it is worth investigating elephant welfare in more detail. Poor well-being is certainly a parsimonious hypothesis for the effects seen, and one now needing more direct test. Such work is needed because, regardless of whether welfare issues are causal, short life-spans, anovulation and stereotypic behavior are all unwanted management problems.

\section{What Next?}

The relative dearth of unambiguous welfare-relevant data is frustrating. It reflects a lack of large-scale empirical research projects - beyond the welcome but somewhat limited Harris et al. [2008] — explicitly aimed at assessing zoo elephant well-being. Several future research approaches would more effectively test hypotheses about population-level welfare.

One group of approaches continues our theme of carefully and statistically comparing zoos with other populations. Data could be collected from zoo and reference populations on variables to confirm (or otherwise) our indices' links with poor welfare: for instance, the degree to which poor immunity contributes to premature adult deaths, the role of infanticide in elevated infant mortality, and the role of stress-induced suppression of maternal oxytocin levels in stillbirths and infant losses. In addition, data are needed on potential confounds that could affect the indices used here, to help identify when factors unrelated to well-being are involved in the population differences. Examples include using records of mating opportunities, to help interpret fecundity data; using records of earlier breeding experience, to help interpret acyclicity and premature reproductive senescence; and 
obtaining measures of obesity, to assess their role in stillbirths and premature adult deaths. A final future comparative approach is to screen zoo and reference populations with additional, independent welfare indices, such as cortisol and catecholamine output, cognitive bias, behavioral indices of fear/conflict, and postmortem measures, such as adrenal weight (see companion article for details). Cortisol might be the easiest because already enough data exist to statistically compare fecal corticosteroid outputs of captive and free-ranging animals, at least for African elephants (see articles cited by Mason and Veasey's companion article, this volume). Harris et al. [2008], who recently assayed fecal corticoids across the UK and Irish zoos, commented that the mean levels for African elephants in this population fall within the range reported in the wild. However, to make such a comparison useful and valid, it would need to select specific, appropriate in situ benchmark populations; be statistical, not descriptive; and also carefully control for any age and sex differences in population structure.

Our other broad research recommendation involves focusing in on the zoo populations themselves. Regional sub-population (Europe vs. North America), timeperiod (e.g. recent/current vs. historical), and species can all clearly influence our indices; and "zoo effects" have also been identified for stereotypic behavior and fecal corticoids [Harris et al., 2008]. The reasons for this variation should now be identified empirically. Note that relevant timescales should be considered here. Thus, for variables where early or cumulative past experience is important (e.g. stereotypic behavior; adult lifespan), this would require tracking down historical information on weaning/import age and past facility design, social environments, and training methods; whereas for stillbirths and infant mortality, dam treatment around the immediate time of parturition might be a fruitful variable to investigate (perhaps more so than long-term housing). Done with care, such studies could both improve best management practice and assess the likelihood that poor welfare per se underlies these temporal, regional, species, and zoo effects.

\section{“Benchmarking": How Should Comparisons With Reference Populations Be Run?}

Using "benchmark" data from well-run sanctuaries, reserves in good habitats, or wild or semi-protected populations from which threats that should be absent in zoos (e.g. deaths from hunting) are statistically removed, is a useful, objective way to assess zoos' performance, and relevant not just for welfare but also for comparing bodyweights and many other variables. Our focus has been elephants, but this approach has been applied to other taxa too [e.g. carnivores: Terio et al., 2000, 2004; Munson et al., 2005; and Clubb and Mason, 2007]. Obviously, valid comparisons must compare like with like (e.g. males with males, females with females, like-aged animals with like-aged animals), use complete datasets, and also test for significance with appropriate inferential statistical tests. However, this article has repeatedly touched on other methodological and interpretative issues this approach can raise, and because they have not been tackled elsewhere, we end by addressing them.

One major issue is that there often will be alternative reference populations to choose between, or judgments to make as to how stringently to statistically remove the impacts of various threats from these populations' data. To illustrate, Clubb et al. [2008, 2009] used MTE data as a benchmark for Asian elephants, even though 


\section{Mason and Veasey}

its population growth is lower and its infant mortality levels higher than some other protected or even wild populations of Asian elephants [its low fecundity compared with Amboseli was certainly evident in Section I; see also Clubb et al., 2009]. Similarly, they used Amboseli as their reference for African elephants, even though other wild African elephants have faster population growth and/or lower infant mortality [see Clubb et al., 2009]. Such choices depend on how high one wishes to set the benchmark (Clubb et al.'s were thus rather conservative), plus practical constraints like access to data. Furthermore, Clubb et al. then factored out deaths caused by humans (presenting these values alongside figures from raw data so that both "low" and "high" benchmarks could be seen). They chose not to additionally remove deaths caused by snake bite or other natural threats absent in good zoos, to avoid accusations of "setting the bar too high." Saragusty and co-workers, in contrast, in their analyses of MTE infant mortality data, did remove such deaths, in order to identify what they judged as more appropriate infant loss rates for a truly optimally cared-for population. As we have seen, such statistical decisions can affect zoos' apparent relative performance. Our view here is not that one decision is wrong and another right, but that, when presented transparently, they yield benchmarks that vary in "height," perhaps usefully regarded as "bronze," "silver," and "gold" standards, or medium-term, long-term and ultimate goals for zoos to aspire to.

Perhaps more controversially, we would like to encourage researchers using this approach to recognize that potential reference populations may perhaps involve elements of lifestyle which are good for some aspects of welfare (thus affecting certain welfare indices positively), and yet be far from ideal in other ways (thus affecting other welfare indices negatively). To illustrate, circus elephants perform more stereotypic behavior than zoo elephants [reviewed by Clubb and Mason, 2002], yet anecdotally have higher fecundity and lower infant mortality. This might suggest aspects of social structure and birth management that should be emulated by zoos while also identifying degrees of confinement or lack of control that should most definitely be avoided. In practice then, the ideal "platinum level benchmark" might potentially comprise data on different variables from different populations, compiled to create a composite view of what animal-based measures should look like in the ideal population.

\section{CONCLUSIONS}

(1) Data on three broad types of welfare index were available for comparing zoo elephants with benchmark populations: data related to reproduction (fecundity, acyclicity, reproductive senescence, and stillbirth rates); mortality (in infant, juvenile, and adult stages); and stereotypic behavior.

(2) Results typically suggest that zoo elephants could have had, or currently may have, poorer welfare than benchmark populations. Although all contrasts except those relating to stereotypic behavior could reflect factors other than poor well-being (e.g. obesity, inadequate reproductive experience, etc.), the most parsimonious explanation is that zoo elephants broadly have experienced poorer standards of welfare than should be expected, given that they are well-provisioned and protected from danger.

(3) In many cases, our "zoo welfare performance" measures displayed variation over time, between regions, and between species, suggesting that these variables are sensitive to local husbandry standards. Optimistically, the evidence suggests improvements in husbandry and potentially welfare in recent years, at least in Europe. 
(4) Further research is much needed. This should test the hypothesis that zoo elephants have substandard welfare more directly, tease out effects of other variables like obesity, and aim to yield husbandry improvements that bring zoo elephant performance to benchmark standards.

(5) "Benchmarking" via carefully chosen reference populations, is a useful, objective methodological approach, although one needing transparency, judgment, and the careful use of appropriate statistical tests.

\section{ACKNOWLEDGMENTS}

Thanks to Janine Brown and Joseph Soltis for their patience and diligence as editors, and to Janine for access to up-to-date data on acyclity in North America. Thanks too to Ann-Kathrin Oerke for very helpful information and insights on acyclity in Europe, to Joseph Saragusty for clarifications on his published "infant mortality" data (and enjoyable e-mail exchanges), to Joyce Poole for discussion on displacement activities in wild free-living African elephants, to Phyllis Lee for calculating what Amboseli lifespans would be if one excluded infant mortality, and to Jamie Dallaire and three referees for very helpful comments on the manuscript.

\section{REFERENCES}

Ahlström S, Jarvis S, Lawrence AB. 2002. Savaging gilts are more restless and more responsive to piglets during the expulsive phase of parturition. Appl Anim Behav Sci 76:83-91.

Bahr NI, Pryce CR, Dobeli M, Martin RD. 1998. Evidence from urinary cortisol that maternal behaviour is related to stress in gorillas. Physiol Behav 64:437-439.

Baird DT, Cnattingius S, Collins J, Evers JLH, Glasier A, Heitmann BL, Norman RJ, Ong KK, Sunde A, Cohen J, Cometti B, Crosignani PG, Devroey P, Diczfalusy E, Diedrich K, Fraser L, Gianaroli L, Liebaers I, Mautone G, Ragni G, Tarlatzis B, Van Steirteghem A. 2006. Nutrition and reproduction in women. Hum Reprod Update 12:193-207.

Berga SL, Loucks-Daniels TL, Adler LJ, Chrousos GP, Cameron JL, Matthews KA, Marcus MD. 2000. Cerebrospinal fluid levels of corticotropin-releasing hormone in women with functional hypothalamic amenorrhea. Am J Obstet Gynecol 182:776-784.

Brown JL, Olson D, Keele M, Freeman EW. 2004a. Survey of the reproductive cyclicity status of Asian and African elephants in North America. Zoo Biol 23:309-321.

Brown JL, Walker SL, Moeller T. 2004b. Comparative endocrinology of cycling and noncycling Asian (Elephas maximus) and African (Loxodonta africana) elephants. Gen Comp Endocrinol 136:360-370.

Cavigelli SA, McClintock MK. 2003. Fear of novelty in infant rats predicts adult corticosterone dynamics and an early death. Proc Natl Acad Sci USA 100:16131-16136.
Cavigelli SA, Yee JR, McClintock MK. 2006. Infant temperament predicts life span in female rats that develop spontaneous tumors. Horm Behav 50:454-462.

Clubb R, Mason G. 2002. A review of the welfare of elephants in European zoos. Horsham, UK: RSPCA.

Clubb R, Mason G. 2007. Natural behavioral biology as a risk factor in carnivore welfare: how understanding species differences could help zoos redesign enclosures. Appl Anim Behav Sci 102:303-328.

Clubb R, Lee P, Mar KU, Moss C, Rowcliffe M, Mason GJ. 2008. Compromised survivorship in zoo elephants. Science 322:1649.

Clubb R, Lee P, Mar KU, Moss C, Rowcliffe M, Mason GJ. 2009. Fecundity and population viability in female zoo elephants: problems and possible solutions. Anim Welf 18:237-247.

Creel SR, Waser PM. 1994. Inclusive fitness and repdroductive strategies in dwarf mongooses. Behav Ecol 5:339-348.

Donaldson R. 2003. Experiences of older burglary victims. Home Office Research, Development and Statistics Directorate, Findings, Vol. 198. London: Home Office.

Faust LJ, Thompson SD, Earnhardt JM. 2006 Is reversing the decline of Asian elephants in North American zoos possible? An individual-based modelling approach. Zoo Biol 25:201-218.

Freeman EW, Weiss E, Brown JL. 2004. Examination of the interrelationships of behavior, dominance status and ovarian activity in captive Asian and African elephants. Zoo Biol 23: 431-448. 
Freeman EW, Guagnano G, Olson D, Keele M, Brown JL. 2009. Social factors influence ovarian acyclicity in captive African elephant (Loxodonta africana). Zoo Biol 23: 431-448.

Gobush KS, Mutayoba BM, Wasser SK. 2008. Long-term impacts of poaching on relatedness, stress physiology, and reproductive output of adult female African elephants. Conserv Biol 22:1590-1599.

Hadley C, Hadley B, Shirley E, Yang M, Lewis MH. 2006. Spontaneous stereotypy and environmental enrichment in deer mice (Peromyscus maniculatus): reversibility of experience. Appl Anim Behav Sci 97:312-322.

Harris M, Sherwin S, Harris S. 2008. The welfare, housing and husbandry of elephants in UK zoos: Final report, University of Bristol. DEFRA Science and Research Project WC05007. London: Department of Food, the Environment and Rural Affairs.

Hartmann U, Hesier K, Ruffer-Hesse C, Klother G. 2002. Female sexual desire disorders: subtypes, classification, personality factors and new directions for treatment. World J Urol 20:79-88.

Hedges S, Tyson MJ, Sitompul AF, Hammatt H. 2006. Why inter-country loans will not help Sumatra's elephants. Zoo Biol 25:235-246.

Hermes R, Saragusty J, Schaftenaar W, Goritz F, Schmitt DL, Hildebrandt TB. 2008. Obstetrics in elephants. Theriogenology 70:131-144.

Kaplan JR, Manuck SB. 2004. Ovarian dysfunction, stress and disease: a primate continuum. ILAR J 45:89-115.

Kiecolt-Glaser JK, McGuire L, Robles TF, Glaser R. 2002. Emotions, morbidity, and mortality: new perspectives from psychoneuroimmunology. Ann Rev Psychol 53:83-107.

Kurt F. 1995. The preservation of Asian elephants in human care: a comparison between the different keeping systems in South Asia and Europe. Anim Res Dev 41:38-60.

Kurt F, Mar KU. 1996. Neonate mortality in captive Asian elephants (Elephas maximus). Z Sauget 61:155-164.

Lair RC. 1997. Gone astray: the care and management of the Asian elephant in domesticity. FAO/ RAP publication 1997/16. Bangkok: FAO Regional Office for Asia and the Pacific, Thailand.

Lee P, Moss CM. 2008. Welfare and well-being of captive elephants: perspectives from wild elephant life histories. In: Forthman DL, Kane L, Waldau PF, editors. An Elephant in the Room: the science and well being of elephants in captivity. North Grafton, MA: Tufts University Cummings School of Veterinary Medicine's Center for Animals and Public Policy. p 23-40.

LeFevre J, McClintock MK. 1991. Isolation accelerates reproductive senescence and alters its predictors in female rats. Horm Behav 25: 258-272.

Leone EH, Estévez I. 2008. Economic and welfare benefits of environmental enrichment for broiler breeders. Poult Sci 87:14-21.
Lockwood CJ. 1999. Stress-associated preterm delivery: the role of corticotropinreleasing hormone. Am J Obstet Gynecol 180:264S-266S.

Mar KU. 2007. The demography and life history strategy of timber elephants in Myanmar [Dissertation: Ph.D. Thesis]. University College London, London, England.

Mason G. 2006. Stereotypic behaviour: fundamentals and applications to animal welfare and beyond. In: Mason G, Rushen J, editors. Stereotypies in captive animals, 2nd ed. Wallingford, UK: CAB International. p 325-356. Mason G, Clubb R, Latham N, Vickery S. 2007. Why and how should we use environmental enrichment to tackle stereotypic behaviour? Appl Anim Behav Sci 102:163-188.

Mason GJ, Veasey J. 2009. How should the psychological well-being of zoo elephants be objectively investigated? Zoo Biol 2009. Published online: DOI 10.1002/zoo.20256

Menec VH, Chipperfield JG. 1997. The interactive effect of perceived control and functional status on health and mortality among young-old and old-old adults. J Gerontol B Psychol Sci Soc Sci 52:P118-P126.

Munson L, Terio KA, Worley M, Jago M, BagotSmith A, Marker L. 2005. Extrinsic factors significantly affect patterns of disease in freeranging and captive cheetah (Acinonyx jubatus) populations. J Wildl Dis 41:542-548.

Oerke A-K. 2004. The reproductive potential of EEP elephant populations. EAZA News 47: 26-27.

Oerke A-K, Heistermann M, Hodges K. 2000. Evaluation of the current breeding status of African and Asian elephant cows in European zoos and circuses based on non-invasive hormone analysis. In: Rietkerk F, Hiddinga B, Brouwer K, Smits S, editors. EEP yearbook $1998 / 99$ including proceeding of the 1999 EAZA conference, Basel. Amsterdam: EAZA Executive Office. p 484- 487.

Oerke A-K, Heistermann M, Hodges K. 2001. Reproductive characteristics of the European elephant population: long-term cycles and pregnancy data based on non-invasive methodology. In: Schwammer H, Foose TJ, Fouraker M, Olson D, editors. Recent research on elephants and rhinos: abstracts of the international elephant and rhino symposium Vienna. Munster: Schuling Verlag. p 26.

Patin V, Lordi B, Vincent A, Thoumas JL, Vaudry H, Caston J. 2002. Effects of prenatal stress on maternal behavior in the rat. Dev Brain Res 139:1-8.

Proctor CM, Freeman EW, Brown JL. 2009. Results of a second survey to assess the reproductive state of female Asian and African elephants in North America. Zoo Biol. Published Online, DOI: 10.1002/zoo.20238.

Roozendaal MM, Swarts HJ, Wiegant VM, Mattheij JA. 1995. Effect of restraint stress on the preovulatory luteinizing hormone profile and 
ovulation in the rat. Eur J Endocrinol 133: 347-353.

Rurangwa E, Kime DE, Ollevier F, Nash JP. 2004. The measurement of sperm motility and factors affecting sperm quality in cultured fish. Aquaculture 234:1-28.

Sanders KA, Bruce NW. 1997. A prospective study of psychosocial stress and fertility in women. Hum Reprod 12:2324-2329.

Saragusty J, Hermes R, Göritz F, Schmitt DL, Hildebrandt TB. 2009. Skewed birth sex ratio and premature mortality in elephants. Anim Reprod Sci 115:247-254. (Published Online Oct 31 DOI:10.1016/j.anireprosci.2008.10.019).

Shaw DC, Gallagher RH. 1984. Group or singlyhoused rats? In: Standards in laboratory management: proceedings of a LASA/UFAW Symposium. Potters Bar: UFAW. p 65-70.

Sheiner EK, Sheiner E, Hammel RD, Potashnik G, Carel R. 2003. Effect of occupational exposures on male fertility. Ind Health 41:55-62.

Sugiura K, Yoshimura H, Yokoyama M. 1997. An animal model of copulatory disorder induced by social stress in male mice: effects of apomorphine and 1-dopa. Psychopharmacology 133:249-255.

Sukumar R. 2003. The living elephants: evolutionary ecology, behaviour, and conservation. Oxford, UK: Oxford University Press.

Sukumar R, Krishnamurthy V, Wemmer C, Rodden M. 1997. Demography of captive Asian elephants (Elephas maximus) in Southern India. Zoo Biol 16:263-272.

Taylor VJ, Poole TB. 1998. Captive breeding and infant mortality in Asian elephants: a comparison between twenty western zoos and three eastern elephant centers. Zoo Biol 17:311-332.

Terio KA, Munson L, Solnick JV. 2000. Infection with H-pylori-like organisms is associated with gastritis in captive but not wild cheetahs. Gastroenterology 118:4035.
Terio KA, Marker L, Munson L. 2004. Evidence for chronic stress in captive but not free- ranging cheetahs (Acinonyx jubatus) based on adrenal morphology and function. J Wildl Dis 40:259-266.

Tuchscherer M, Kanitz E, Otten W, Tuchscherer A. 2002. Effects of prenatal stress on cellular and humoral immune responses in neonatal pigs. Vet Immunol Immunopathol 86:195-203.

Vitetta L, Anton B, Cortizo F, Sali A. 2005. Mindbody medicine: stress and its impact on overall health and longevity. Ann NY Acad Sci 1057: 492-505.

von Borell E, Dobson H, Prunier A. 2007. Stress, behavior and reproductive performance in female cattle and pigs. Horm Behav 52:130-138.

Wiebold JL, Stanfield PH, Becker WC, Hillers JK. 1986. The effect of restraint stress in early pregnancy in mice. J Reprod Fertil 78:185-192.

Wiese RJ, Willis K. 2004. Calculation of longevity and life expectancy in captive elephants. Zoo Biol 23:365-373.

Wingfield JC, Sapolsky RM. 2003. Reproduction and resistance to stress: when and how. J Neuroendocrinol 15:711-724.

Wisborg K, Barklin A, Hedegaard M, Henriksen TB. 2008. Psychological stress during pregnancy and stillbirth: prospective study. BJOG 115:882-885.

Wittemyer G, Daballen D, Rasmussen H, Kahindi O, Douglas-Hamilton I. 2005. Demographic status of elephants in the Sambusu and Buffalo Springs National Reserves, Kenya. Afr J Ecol 43:44 47.

Wuerbel H, Stauffacher M. 1998. Physical condition at weaning affects exploratory behaviour and stereotypy development in laboratory mice. Behav Proc 43:61-69.

Zedrosser A, Dahle B, Stoen OG, Swenson JE. 2009. The effects of primiparity on reproductive performance in the brown bear. Oecologia 160: $847-854$. 